will be seen, were the cases of short duration. This clearly indicates that oligopnoea is due mainly, if not entirely, to the morphine. $1 \mathrm{am}$ not suggesting that this slight degree of oligopnoea is critical, for $I$ have intentionally refrained from interference, though prepared to resort to artificial respiration if necessary, but the condition of the infants was never alarming. Only in two cases have I resorted to artificial respiration-one a difficult forceps extraction, and the other a case in which the cord was three times round the neck of the infant. Both cases recovered.

\section{Effect on the Mother.}

I have made it a constant practice to begin this treatment early, uften as soon as labour had definitely begun. In a few of the cases there appeared to be slight retarda. tion of the uterine contractions after the initial dose, but after it only. My experience has been that after the second and subsequent doses the contractions have become normal, and in not a few cases - really severe. I feel justified in saying this has probably quickly regained the little time that may have been lost, and therefore labour on the whole has not been retarded. Possibly, in the few cases where an initial delay appeared to occur, there was present some slight idiosyncrasy to morphine.

Perhaps the most striking after-effect on the mother is the remarkable absence of exhaustion and shock. After a labour lasting twenty-four to forty-eight hours or more the patient will often sleep a few hours, and on awaking be astonished that labour is over, and have such a feeling of well-being that she cannot realize anything has occurred.

So long as complete amnesia, and not analgesia, is aimed at and maintained, $I$ have no hesitation in saying my experince proves that there is no risk either to mother or infant. If pushed to the slightly further stage of analgesia the risk may be grare; but as the margin between amnesia and analgesia is small, the necessity for constant watchfulness by the obstetrician is all the more emphasized.

The influence on the pulse is interesting. In $11_{3}^{2}$ per cent. of the above 150 cases the pulse-rate was in. creased; in 36 per cent. it remained the same; in the remaining $52_{3}^{2}$ per cent. it was diminished. In all the cases except two the character of the pulse was at least as good as at the onset of labour; usually it was improved. The two exceptions were cases complicated by influenza and an acute attack of cholelithiasis respectively.

While my next observation ma $r$ not be of any particular tochnical interest, it is certail $y$ of some moment from a national point of view at the , isent time. In this serics of 150 cases I have certain litowledge that in nine the parents.had resolutely refused to entertain the idea of a child. Hearing of the scopolamine-morphine treatment, they decided the time was ripe to embark upon the responsibilities of parentage. The result is an increase of 6 per cent. in the birth-rate in this series. This figure three times covers the infant mortality at birth in the 150 cases, and is rather significant.

\section{THE INTRAVENOUS INJECTION OF TISOL IN THE TREATMENT OF GENE: IL SEPSIS,}

As Illustrated BY Two Cases of Septic Otitid THROMBOSIS OF THE SIGMOID SINUs. EY

J. S. FRASER, M.B., F.R.C.S.E., ASBISTANT SERGEOY:

ANDREW CAMPBELL, M.B., AND E. D. D. DICKSON, CLINICAL AssistiNTs,

TAR AND THROAT DEPARTMEYT, ROTAL INITIIJART, EDINBCRGH.

(From the Ear and Throat Department, Roral Infirmary, Edinburgh, under the charge of A. Logan Turner, M.i., F.R.(.S.E., F.R. -.E.)

THE method of treating generalized sepsis by the injection of the blood with a solution of hypochlorous acid in the form of eusol was introduced by Lorrain Smith, Ritchie, and Rettie, who described the recovery under this form of treatment of a case of grare puerperal septicaemia. ${ }^{2}$ They pointed out that the most probable interpretation of the result was that the hypochlorous acid destroyed toxin circulating in the blood, and that there was no evidence that the eusol injected acted as a bactericide.

The following two cases illustrate the application of the method to the generalized sepsis which follows otitic thrombosis of the sigmoid sinus. They aro examples of somewhat different types of sepsis. In the first, after the operation there was, apart from a patch of pleurisy, no sign of the derelopment of secondary foci of infection. The symptoms of blood sepsis were, however, very marked, and the patient had passed into a desperate condition; the treatment by eusol injection was applied at this stage. In the second case a large focus of sepsis developed in the right ilium. The injection of eusol produced only tem. porary benefit. When this focus was drained, however, the patient recovered.

It may be concluded that the presence of a large septic focus is a condition which cannot be alleviated by intravenous injection of eusol. To neutralize toxin in the blood, even by repeated injections of eusol, is insufficient to control the toxaemia in such a condition, becauso the local focns still remains active, and continually adds new toxin to the circulation. The contrast between these cases furnishes a suggestion as to the type of septic infection in which ensol injection is of value.

\section{Case I.}

R. W., male, aged 6 rears, was first seen on October 8th, 1910 suffering from chronic discharge from the right ear. sufering from chronic discharge from the right ear. The right sent to the ward for adnission, but, as he cried, his mother refused to leare him. He was brought back six rears tater refused to leave him. He was brought back six years later (April 7th, 1916) complaining of pain in the right ear of three
weeks' duration. He had had a rigor wheu the pain began, and weeks' duration. He had had a rigor wheu the pain began, and
now suffered from pain in the neck, frontal headache, drovst. now suffered from pain in the neck, frontal headache, drowsi
ness, and mild delirium. There was no history of recent vomiting or giddiness.

On admission the temperature was $99^{\circ} \mathrm{F}$., the pulse 100 , and the respirations 24 . The boy looked foightened, restless, and kept his head flexed; the tongue was moist but slightly furred. There ras still a polrpus in the right meatus and tendernes. was present on pressure one inch behind the right mastoid.

Functional examination of the cochlear apparatus showed that the right ear was tion of the cochlear apparatus showe hat the right ear was guite deaf (complete deafness with the noise apparatus in the good ear). Examination of the vestibular abparatus shorred complete loss of reaction, bnt there was no an old destruction of the inner ear.

\section{First Operation.}

On the erening of admission the temperature rose to $102.4^{3}$ and on the following day the first operation was performed (J. S. F.). The mastoid cortex showed two large holes through which cholesteatoma protruded, but there was no subperiosteal abscess. In removing the mastoid cortex the sigmoid sinus, which was exposed in the posterior part of the greatly enlarged mastoid carity, was injured in the region of the upper knee and mastoid carity, was injured in the region of the upper lonee and
bled frecly. After controlling this haemorrhaje the radical operation was completed-the malleus and incus being absent. operation was completed-the malleus and incus being absent. It was now seen that the lateral semicircular canal had been opened by the cholesteatoma. Accordingly the labyrinth opera-
tion (Neumann) was performed. The sigmoid sinus ivas not tion (Neumann) was performed. The sigmoid sinus was not further investigated at this time. The operation cav
packed with iodoform worsted and the wound left open.

packed with iodoform worsted and the wound left open.
The boy hn: $t$ a good night; no rigor or vomiting. The hear on April $Q, i$ was still tucked forward. At 8 p.n. the temperat uic rose to $104.4^{\circ} \mathrm{F}$

On April loth blood was taken from an arm rein for culture. The report received later stated that a Gram-positive staphy. lococcus and a Gram-negative bacillus were present. On lumbar puncture the fluid spurted ont under great pressure, but was quite clear, and a report received later stated that there was no c...eess of cells and no organisms on culture.

\section{Second Operation.}

As the patient's general condition was unsatisfactory aud the temperature swinging, the lateral sinus was exposed in a back ward direction until healthy wall was reached. The jugnlar ward direction until healthy wall was reached. The jugthlar bulb end of the sinus was also further exposed. The anterior: wall was slit up and \& partly organized clot found. Free bleeding ras obtained from the upper end, which was occluded
by packing. Towards the bulb apparently healthy red clot way by packing

On April 11th lie felt better, and the temperature wa: 98", but next day it rose at $4 \mathrm{p} . \mathrm{m}$. to $103^{\circ}$, and at $81 \mathrm{l} . \mathrm{m}$. to $105 \mathrm{l}$.

\section{Third Operation.}

On $A$ pril 13th the right internal jugular vein was exposel and found to be clotted down to the juuction with the common facial. The rein was diviled between ligatures and the mper end opened and stitcheil to the skin. Both mostoid and ueck wonnds were left open. On April 15th his condition was fairl. satisfactory. The jugnlar bulb was washed through front satisfactory. The jug
mastoid wound to neck.

On April 18th and 19th the evening temperature was elerated, and on April 20th it reached $104 \%$. The wounds showed no 
reaction. On April 21st, under a general anaesthetic, blood was again removed for culture, and the presence of a Gram p si ive streptococcus, a Gram-negative bacillus, and a Gramn gitive diplococcus reported.

attempt was now made to inject eusol in the usual way into a vein, but, owing to the collapsed state of the veins, the procedure failed. It was noted that whenever iodine was

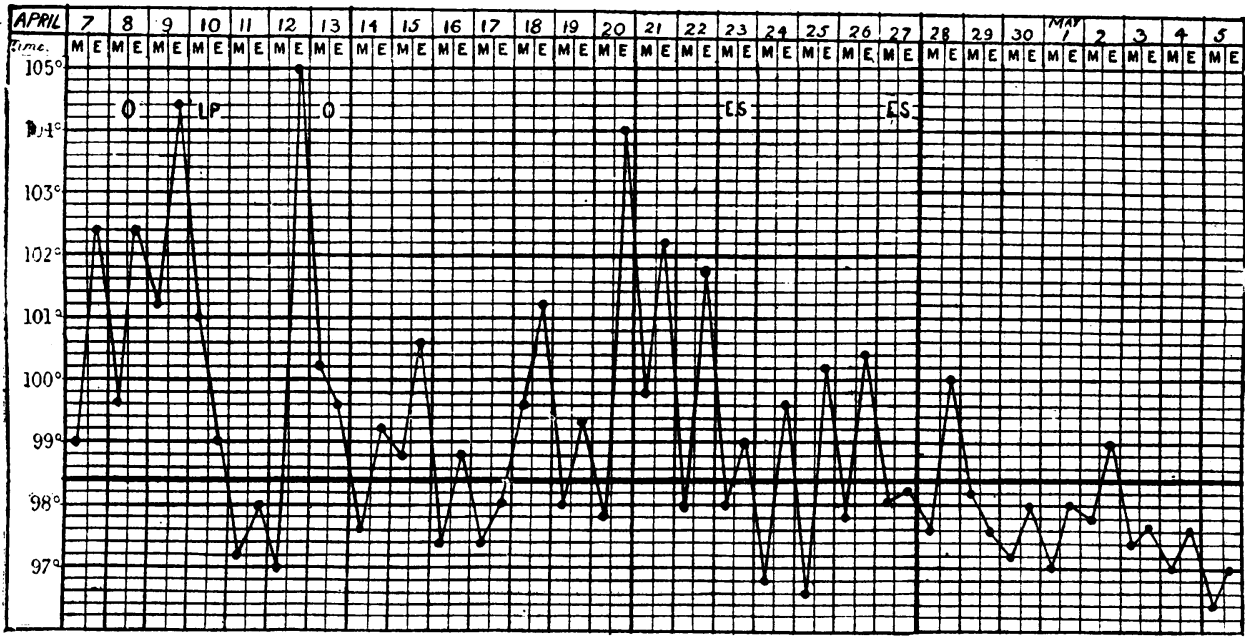
Curart 1.-R. W. O. = Operation. L.P. = Lumbar puncture. E.S. = Intravenous injection of eusol
and saline. On April 7 th, urotropin gr. v was given four-hourly.

CASE II.

J. M., male, aged 16 years, was admitted on January 25 th, 1916, suffering from discharge from the right ear of three years duration. For the last five days he had had pain in the right ear and right side of the head, and had suffered from shivering and vomiting. The temperature on admission was $98^{\circ} \mathrm{F}$., and the pulse 72. The patient locked ill, and the tongue was furred though moist.

Examination showed pus in the right external meatus, with marked mastoid tenderness. Owing to narrowing of the meatus the drumhead ' could not be seen. Functional examination revealed middleear deafness on the right side, with a normal vestiside, with a normal vestiafternoon the temperature rose to $101.6^{\circ}$, and the pulse was feeble and irregular.

\section{First Operation.}

On operating at $5.30 \mathrm{p} . \mathrm{m}$. the mastoid cortex was found normal, while the antrum contained granulation tissue. The attic and aditus showed cholesteatoma, and the incus was absent. The labyrinth wall was healthy. On removing the bone in a backward direction from the antrum, a large perisinus abscess a large perisinus abscess was evacuated (StaphyloThe sigmoid sinus was

applied to the skin over the cubital, raphenous, or external jugular veins these vessels at once disappeared. In the evening

On April 23rd the temperature was still elevated and the patient apparently in a dying condition. As a last resort the median cephalic vein was cut down on and $60 \mathrm{c.cm}$. of eusol and lukewarm saline solution (equal parts) were injected by Dr. Camplell. Next day the patient looked better; the tongue it was noted that since the injection of eusol the evening temperature had not been so high as formerly, but had risen each night a little higher than on the preceding evening (see Chart). Accordingly, a second injection of eusol was given by Dr. Campbell after an arm vein had been exposed under general anaesthesia. On May 31 it was noted that there had been satisfactory progress for the last five days, but on May 5th the boy complained of slight pain at the left base, and the exploring needie withdrew. a little serous fluid which contained a Grampositive diplococcus and a Gram-negative bacillus. On May 9tha second puncture of the left pleural cavity showed that the absorbed.

On May 15th a plastic operation to close the wound behind the left ear was performed; the neck wound had now been healed for some time.

The case illustrates the danger of refusing operation when chronic middle-ear suppuration is associated with cholesteatoma and aural polypus. The onset, six year's later, of septic thrombosis of the sigmoid sinus was typical-earache, shivering, and stoppage of purulent discharge.

The cessation of the discharge appears to us to liave been due to the toxic condition of the patient and the consequent want of reaction, and not, as is usually supposed, to any obstruction to the outflow. It was obvious from the history, functional examination, and conditions found at operation that the right labyrinth had been destroyed for some considerable time. The free bleeding from the sigmoid sinus at the first operation led to regrettable delay in the opening up of this vessel. Further, as subsequent events proved, it would have been better if the jugular vein had also been ligatured at the same time. Lumbar puncture revealed the presence of benignant serous meningitis, which was no doubt associated with the condition of the sinus and of the dura mater of the posterior cranial fossa. It was obvious at the second operation that the sinus thrombosis must have existed for some time. In spite of the clearing out of the sigmoid sinus and the jugular ligature, the patient on April 23rd appeared to be in a dying condition. The improvement following the first intravenous injection of eusol was very marked, while after the second injection recovery was rapid and was only interrupted for a day or two by a slight attack of pleurisy (infarct?). freely exposed, and granulations noted on its anterior wall. The sinns was painted with iodine and slit up. Free bleeding was obtained from the torcular end, but not from the aureus; (2) a Gram-positive streptocciccus; (3) a Gram-positive diplobacillus.) As the clot in the region of the bulb appeared to be healthy, the internal jugular vein was not ligatured. The wound was left open. At the end of the operation a blood culture was made, and the report received later showed that Staphylococcus alu'eus was present.

He had a bad night, and next day complained of frontal headache. At 4 p.m. the temperature rose to $102^{\circ}$. Lumbar puncture showed that the cerebro-spinal fluid was not under tension. The fluid, however, did not reduce Fehliug's under tension. direct films showed a few Gram-positive cocci. No growth was direct films showed a

On January $28 \mathrm{th}$ he complained of pain at the base of the right lung and in the right hip. A needle was inserted through the pleura, but no fluid was withdrawn. On January 30 th he felt sick and complained of backache and of double vision. As he was very nervous the wound was dressed under a general anaesthetic ; it looked inactive, and the sinus wall was sloughy. Free bleeding was obtained from the upper end of the sinus on removal of the plug.

\section{Second Operation.}

On January 31 st the tsmperature rose to $102^{\circ}$ at 10 a.m. The internal jugular vein was ligatured after tying off the common

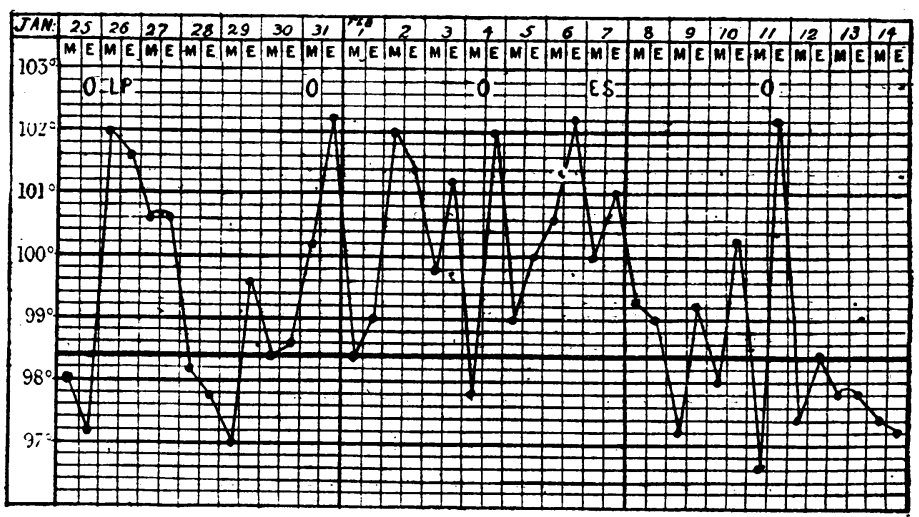

Chart 2.-J. M. O.= Operation. L.P. = Lumbar puncture. E.S. = Intra-

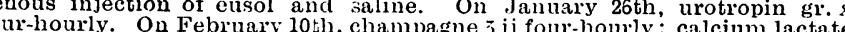
$\mathrm{v}$ four-hourly.

facial. A clot was removed from the upper end of the vein which on culture yielded Stapinylococcus aureus along with streptococci.

On February 2nd it was noted that the patient had a characteristic "sweetish" septic smell. He still complained of pain in the right hip, and the right ilium was very tencier. The movements of the hip-joint were free. The temperature on this morning - was $102^{\circ} \mathrm{F}$. The patient was examined by $\mathrm{Mr}$. 
Struthers, who found no redness, swelling, or fluctuation in the region of the hip, and advised against interference at that time.

On February 4th it was noted that the temperature was still rising each evening. Fluctuation was evident over the right the Staphylococcus atrens. A drainage tube was inserted. Pus was daily evacuated on washing through the jugular bulb. The temperature continued to swing, and the patient still complained of pain in the right hip.

On February 7 th he complained of pain in the right knee. Professor Lorrain Smith was consulted regarding the intravenous injection of eusol, and at $5 \mathrm{p.m}$. blood was withdrawn from an arm vein, and thereafter $50 \mathrm{c.cm}$. of eusol and normal saline were injected. (On culture the blood vielded a Grampositive staphylococcus and a Gram-positive bacillus.)

\section{Third Operation.}

On February 11th it was noted that the temperature was still swinging, that the wounds showed little reaction, and the patient still complained of severe pain in the right hip, and kept the right $\mathrm{hip}$ and knee joints flexed. Mr. Struthers made an incision over the right ilium, and exposed the bone freely. When the gouge was inserted pus oozed out of the bone. The jlium was accordingly pierced, and a free flow of pus obtained from a large abscess between the anterior surface of the ilium and the iliacus muscle. 'The hole in the bone was enlarged, and the abscess cavity washed out with eusol. 'I'wo drainage tubes were inserted, and thereafter the cavity was syringed out with eusol twice daily.

On February 15th the temperature was normal, the wounds granulating well, and the patient could keep his right leg granulating well, and the patient could keep his right leg extended. Next day he vomited in the morning, and was rather
drowsy. The optic discs were examined by Dr. Traquair, who frowsy. The optic discs were examined by $\mathrm{Dr}$.

On February 25th it was noted that tine temperature continued normal, that drowsiness had passed off, that the neck and hip wounds were closing rapidly, and that the general condition was satisfactory.

\section{Fourth Operation.}

On March 27th the wound behind the right ear was closed, and the patient was dismissed on April 15th with all wounds healed, except for a small opening behind the right ear.

The patient was a feeble, badly nourished boy. The case was one of extradural perisinus abscess, with secondary thrombosis of the sigmoid sinus. The chief infecting organism appcar's to have been the Staphylococcus aureus. As events showed, it would have been better had the jugular vein been ligatured and divided at the first operation; but the question "when to ligature the jugular" has not yet been finally decided.

The presence of bacteriaemia was not known at the time of the first operation, which was performed shortly after admission. Symptoms of metastasis in the right ilium developed two days after operation, but the condi. tion was not definitely diagnosed till somé days later. 'The fact that the metastasis occurred in bone is what we should expect considering the nature of the infecting organism (staplyylococcus). As far as we know, no satisfactory explanation has been given for the fact that in staphyloeoccic pyaemia metastases cccur in the bones, whereas in streptococcal pyaemia of otitic origin they oecur in the lung-pleuropneumonia and cmpyema. It has been suggested that small emboli may pass through the pulmonary capillaries, whereas large ones are arrested there. Further, the bone mariow may be a locus minoris resistentiae for the staphylococcus. In view of the condi. tion of the right ilium, it was only to be expected that ligature of the jugular vein and intravenous injection of eusol should fail to stop the disease process. It was only when a large hole was made in the ilium and the abscess evacuated that the patient began to improve. Recovery was interrupted for a day or two by an attack of cerebral oedena, the origin of which is somewhat difficult to explain in view of the time which had elapsed between tho complete blockage of the sigmoid sinus and the onset of the drowsy condition associated with oedema of the optic discs. Cholked disc is commoner in sinus thrombosis than in temporo-sphenoidal or cerebellar abscess. Ruttin attributes the condition of the dises to engorgement of the cavernous sinus due to blockage of the superior and inferior petrosal sinuses following obstruction of the sigmoid sinus and jugular bulb respectively.

If the superior longitudinal and straight sinuses always divided into equal branclies at the torcular, it is probable that little disturbance would arise from thrombosis of one sigmoid sinus or ligature of one internal jugular rein. Ruedinger, lowever, has shown that the blood from the superior longitudinal sinus as a rule flows mainly into the right lateral sinus, which, in most cases, is larger than tho left. The straight sinus at times becomes continuous witl the left lateral sinus, but as a rule it divides-the smaller branch going to the right lateral sinus and the larger to the left. 'Ihrombosis of one lateral sinus or ligature of one internal jugular vein (right or left respectirely) may thus interfere with the venous return firom (1) the surface of the brain in cases in which the superior longitudinal sinus becomes continuous with the right lateral sinus; or (2) the deeper parts of the brain when the straight sinus becomes continuous with the left lateral sinus. Iinser has shown that ligature of the right internal jugular vein in cases where it is much larger than the left may produco fatal cerebral oeclema.

[The writers wish to express their best thanks to Professor Lorrain Smith and Dr. Theodore Rettie for their adrice and assistance with regard to the intravenous injection of cusol to Miss Mabel Fitzgerald for her careful investigation of the bacteriology of these two cases; and to Dr. Logan 'I'urner for his kind permission to record the histories of the paticnts.

1 British Medical Joursal, November 13th, 1915.

\section{ACU'TE IIATMORRHAGIC PANCREATITIS : LAPARO'TOMY : RECOVERY.}

BY

G. W. KILNER CROSLAND, D.S.O., M.R.C.S., L.R.C.P., SCIRGEON, HUDDEISFIELD INFIRAIATY.

Cossideris; the gravity of this disease, the difficulty in diagnosing it before operation, and its high mortality, the following account of a case which recovered under sturgical treatment may be of interest.

R. L., millworker, female, was sent to the Hudlersfield Royal Infirmary by Dr. Brown, suffering from an acute abdomiinal catastrophe, thought to be a lerforation of an ulcer of the
stomacl.

Previous Histor!!.

Her gencral health had been fairly good, with the exception of dyspeptic symptoms, from which she had suffered since early life, "bilious attacks" and the rising of sour fluid into the mouth being frequent. Iately these symptoms had not been so marked, and for months before the present illness she had been free from them until two or three days ago, when she had been free from them until two or three days ago, whef she had
an attack which caused her to stay in bed for a day. She had an attack which caused her to stay in bed for a day. She had always been a hard worker, and stated bhat tea and toast
had been a great element in her meals. She was in the hospital had been a great element in her meals. She was in the hospita
in the summer with a small tuberculous abscess in the neck.

History of Present ellness.

On November 10th, 1916 (the day before admission), while at work in the mill, she was lifting a basket, and in the act of stooping felt " the blood rush to her head," and a hard swelling rise up in the boly. To ease herself she undii her corsets; there was a little pain and she felt unw ell, and decided to go home. Her fellow workers state that she looked very ill. On the way home she vomited ceveral times, and had severe pain in the back between the shoulders; on reaching home she was so ill and weak that she could not stand; her sensations were mixed, and she could scarcely descrilie them; she lad " a burning all over," and an inclination to cry out. The next morning she orer," and an inclination to cry out. The next morning she again felt "something rise up inside her," the pain increased; and became localized in
felt tense and swollen.

Cbndition on Admission.

Pulse 160, temperature 98.8. She looked extremely ill and was in great distress; the abilomen was acutely distencled (especially above the umbilicus), rigid, and tender. The breathing was entirely thoracic; she complained of pain in the epigastric region. She was retching a little, and there was tetany in both arms, increasing in spasms every few minutes. She presented the picture of a very acute abdominal
catastrophe, and a provisional diasnosis of a perforated ulcer of the npon.

\section{Operation.}

Within an hour of admission she was anaesthetized and the abdomen opened by an incision above the umbilicus. On opening the peritoneum, a quantity of blood-stained fluid escaped, and a very greatly distended stomach presented through the wound ; there was obviously no perforation in it. It was so much distended that, in order to save time and to prevent damage in returning it, I punctured with a large trocar; it collapsed, the distension being due entirely to gas. The snall hole was closed with an encircling suture and the stomach easily returned to the abdominal cavity. On further examination, fat necrosis was seen in the great omeutum and the transverse mesocolon. The pancreas was enlarged and there were extensive haemorrhages in this region and in and transicrse mesocolon extending to the large intestine; the 